\title{
Pilares para a compreensão da autogestão: 0 caso de um programa de habitação da Prefeitura de Belo Horizonte*
}

Cleiton Fabiano Klechen**

Raquel de Oliveira Barreto***

Ana Paula Paes de Paula****

Sumário: 1. Introdução; 2. Percurso teórico; 3. Metodologia; 4. O caso do Programa de Autogestão da Habitação; 5. Considerações finais e sugestões para novas pesquisas.

Summary: 1. Introduction; 2. Theoretical Path; 3. Methodology; 4. The case of Self-management Housing Department; 5. Final considerations and suggestions for further researches.

Palavras-chave: autogestão; pilares; habitação.

KEY WORDS: worker's self management; segments; housing.

A relevância da autogestão tem despertado estudos e discussões sobre o tema no âmbito da academia, principalmente no que diz respeito à sua proposta de mudança social. A partir de uma revisão da literatura e da análise de algumas experiências autogestionárias, defende-se a ideia de que a gestão autônoma repousa sobre três pilares: 1) autonomia e equidade no processo decisório; 2) valores humanistas e 3) disponibilidade de conhecimento técnico-administrativo para os membros da organização. O objetivo deste artigo é, portanto, analisar a experiência do Programa de

* Artigo recebido em fev. 2009 e aceito em nov. 2010.

** Graduado em administração pela Universidade Federal de Minas Gerais (UFMG). Endereço: Av. Antônio Carlos, 6627, sala 4062 - Pampulha — CEP 31270-901, Belo Horizonte, MG, Brasil. E-mail: cleiton.klechen@gmail.com.

*** Mestranda em administração pela UFMG. Endereço: Rua Icaraí, 469, ap. 202 - Caiçara — CEP 30770-160, Belo Horizonte, MG, Brasil. E-mail: admraquelf@hotmail.com.

**** Doutora pela Universidade Estadual de Campinas (Unicamp). Pós-doutorado pela Fundação Getulio Vargas (FGV-SP). Professora adjunta da Faculdade de Ciências Econômicas da UFMG. Endereço: Rua Governador Mário Covas, 28, ap. 202 - Castelo — CEP 30840-505, Belo Horizonte, MG, Brasil. E-mail: appaula@face.ufmg.br. 
Autogestão da Habitação, da Secretaria Municipal de Habitação de Belo Horizonte, à luz destes pilares definidos pelos autores. De forma geral, percebeu-se que a vivência dos pilares não se dá de forma completa, o que de certa maneira impede que a autogestão seja exercida integralmente. No entanto, argumenta-se que tal forma de gestão cria um vínculo identitário-afetivo das pessoas com o imóvel e contribui para o desenvolvimento da cidadania, os quais se destacam como aspectos positivos do programa.

Segments for the understanding of worker's self management: the case of Belo Horizonte housing department

The relevance of the worker's self management has inspired studies and debates in the scope of the academy, mainly in respect to its proposal of social change. From a revision of the literature and the analysis of some worker's self management experiences, it is supported the idea that it has three segments: 1) autonomy and power equality in the decision making process; 2) humanistic values and 3) technical-management knowledge available for the members of the organization. The objective of this article is to analyze the experience of the worker's housing self management program, of Belo Horizonte Housing Department, through these segments defined. It was observed that these segments were not fully exercised which was an obstacle for the worker's self management process. However, it is perceived that such process creates an emotional identity bond between workers, which contributes for the development of citizenship, what is interpreted as a positive aspect of the program.

\section{Introdução}

A questão da autogestão vem sendo bastante discutida no âmbito da academia, uma vez que as recentes experiências de economia solidária e de cooperativismo trouxeram o assunto de volta à pauta de discussões. De um modo geral, dois posicionamentos costumam ser defendidos. De um lado, busca-se conciliar as práticas de heterogestão e de autogestão para um melhor funcionamento do sistema capitalista e, de outro, busca-se a autogestão como uma alternativa a este sistema. Este segundo posicionamento se alinha à ideia de uma proposta mais ampla de mudança social, que se acopla à economia solidária, frequentemente apontada como uma nova utopia.

De um modo geral, as propostas autogestionárias não chegaram a se desenvolver mais amplamente, o que marginaliza esta forma de gestão ante a presença maciça de organizações heterogeridas (Motta, 1986). Os motivos históricos que levaram a este quadro geralmente relacionam-se a contextos conturbados e à fragilidade das iniciativas adiante da conveniência do mercado. Cabe ressaltar que as dificuldades enfrentadas por estas propostas estão, 
também, ligadas à institucionalização dos valores da sociedade capitalista, da forma heterônoma de gestão, e às consequências originárias desse processo, como a desqualificação do trabalhador, impedindo uma maior consciência política e participativa e estimulando o individualismo e a competitividade.

A forma de gestão autônoma é, portanto, uma realidade que ainda precisa ser mais explorada, e, dado seu potencial para a transformação social e a mudança de valores, surge como uma alternativa viável para a solução de diversos problemas oriundos da gestão heterônoma. No âmbito dos estudos organizacionais, o desenvolvimento dessa abordagem torna-se adequado à compreensão de novas formas de organização que representam possibilidades concretas de transformação social e de emancipação humana. Já no campo da gestão pública, a autogestão pode contribuir para aprofundar as práticas participativas na medida em que apontam para a democracia direta e o engajamento da sociedade civil. No entanto, quando as experiências são apenas residuais, sem estarem conectadas a um projeto maior de sociedade, há o risco de as mesmas serem, por exemplo, formas de desresponsabilizar o Estado. Neste sentido, buscou-se encontrar experiências que pudessem elucidar como a autogestão vem sendo utilizada na gestão pública, questionando principalmente se as mesmas representam de fato experimentos autogestionários.

Com o intuito de aprofundar este questionamento, elaborou-se um referencial teórico para avaliação da gestão autônoma e aplicou-se em um caso real. Dessa forma, o objetivo deste artigo é analisar a experiência do Programa de Autogestão da Habitação, da Secretaria Municipal de Habitação de Belo Horizonte, à luz de pilares da gestão autônoma que os autores definiram a partir de uma revisão da literatura sobre o tema. Este trabalho está estruturado em cinco partes, incluindo esta introdução. Após esta, apresenta-se o percurso teórico realizado para a elaboração dos pilares da gestão autônoma. $\mathrm{Na}$ sequência são explicitadas as escolhas metodológicas. Na quarta parte realizase a análise dos dados e, em seguida, as considerações finais e as sugestões para novas pesquisas.

\section{Percurso teórico}

\subsection{Gestão autônoma: uma contextualização}

A autogestão, segundo Misoczky e colaboradores (2004), consiste na gestão dos meios de produção e organização social em que todas as entidades de base (indivíduos, grupos, movimentos populares) têm direitos e participação 
iguais, pautando-se nos princípios da liberdade e da igualdade. Partindo-se de tal concepção fundamentada na equidade, argumenta-se que a autogestão não se faz sem participação, no sentido que Baeta e Siqueira (1984) apresentam. Para as autoras, a participação é um processo eminentemente político, que supõe que todas as pessoas afetadas por uma determinada decisão devem estar, de algum modo, envolvidas no processo decisório. Implicitamente, supõe-se que toda pessoa é capaz de conscientemente escolher o que é bom para ela, dispensando autoridades de "saber reconhecido" que lhes digam quais são suas reais necessidades.

Os níveis de participação podem ser incluídos no interior de um continuum que vai da heterogestão (onde não existe participação real dos funcionários e todas as decisões são conduzidas pela gerência) à autogestão (onde há o efetivo exercício do poder pelos trabalhadores, comandando todas as decisões). Entre estes dois extremos existem outras formas de gestão, entre as quais se destacam a cogestão e o controle operário apresentados por Guillerm e Bourdet (1976), nos quais a participação se dá de forma pontual e limitada.

A gestão autônoma seria, portanto, o nível mais avançado de democratização em que o controle da organização é realizado por todos os participantes, de modo que as decisões representem a vontade da maioria. Neste sentido, argumenta-se que a autogestão é incompatível com o modo capitalista de produção e que, portanto, esta se relaciona com outras formas de organizações econômicas e sociais como os empreendimentos da economia solidária e as propostas anarquistas.

As características apresentadas nestas formações econômicas, se não podem ser diretamente vinculadas à proposta autogestionária, ao menos correspondem, em grande parte, aos princípios e valores norteadores da autogestão. França Filho e Laville (2004) definem a economia solidária como um fenômeno caracterizado por iniciativas de grupos civis autônomos, que visam desempenhar atividades econômicas de maneira diferente daquela praticada pelo mercado. A proposta consiste na busca por objetivos econômicos através da manutenção de laços pessoais e da disseminação de princípios como a solidariedade. Singer (2002) explicita que as organizações características da economia solidária são propriedade de todos os membros, nas quais há uma gestão democrática e uma distribuição mais igualitária da riqueza gerada, sendo a cooperativa autogestionária o tipo ideal de empreendimento solidário.

De acordo com Garcia (1981), as cooperativas são organizações de pessoas que se unem com o objetivo de atender certas necessidades econômicas fundamentais, em bases de gestão democrática. Nesses empreendimentos, os ideais de solidariedade humana, conduta ética e justiça social são presentes 
e orientam uma produção equitativa, subordinando os motivos econômicos. Além desses fundamentos, existem sete princípios orientadores da proposta, entre os quais se destaca o controle democrático pelos membros. Neste sentido, a autogestão aparece relacionada com a proposta cooperativista como um todo, além de estar entre os princípios norteadores da mesma.

Ressalta-se que os empreendimentos solidários e, de forma mais específica, as cooperativas enfrentam inúmeras dificuldades por vivenciarem princípios e valores contraditórios aos predominantes na sociedade baseada na lógica do mercado. Nesse sentido, as cooperativas seriam "ilhas de autogestão" no seio de um sistema capitalista, restringindo as práticas autogestionárias a uma unidade produtiva. No entanto, Berthier (2002) e Motta (1986) argumentam que o verdadeiro caráter da autogestão é dado pela organização geral da sociedade sob esse regime e, desse modo, tal forma de gestão ultrapassaria os marcos estritos das reivindicações econômicas e sociais, buscando a liberação total da sociedade. É essa a perspectiva da autogestão que permeia as diversas escolas do pensamento anarquista.

A ligação entre anarquismo e autogestão funda-se na primazia de princípios e valores como a igualdade e a liberdade, que orientam a formação de indivíduos com elevado grau de autonomia e de consciência política. Estes são capazes de agir coletivamente de modo a preservar sua individualidade e singularidade pessoal, ao mesmo tempo que se associam para a determinação conjunta da produção e da distribuição das riquezas e dos meios necessários à vida.

Ainda nesta perspectiva mais ampla de autogestão, a literatura descreve experiências que vêm marcando a história, como a espanhola (Mintz, 2002), a iugoslava (Venosa, 1982; Almeida, 1983; Guillerm e Bourdet, 1976), os casos da Rússia (1905 e 1917), da Comuna de Paris (1871), da Hungria (1919 e 1956), da Argélia (1962), da antiga Tchecoslosváquia (1968), da Polônia (1956 e 1980-81), entre outros (Nascimento, 2004b; Guillerm e Bourdet, 1976). Embora essas experiências não tenham alcançado seus objetivos na totalidade, por motivos diversos, as mesmas se diferenciam da gestão heterônoma e apontam para uma possibilidade de ruptura com o modelo vigente.

Pode-se perceber que a autogestão se faz presente em diferentes contextos e pode ser compreendida de formas distintas, principalmente quanto à sua dimensão. Argumenta-se, no entanto, que tal diversidade pode culminar em sua utilização inadequada, fazendo com que, muitas vezes, experiências se intitulem autogestionárias enquanto constituem-se, na realidade, modelos de heterogestão disfarçados, os quais propõem uma participação enganosa dos indivíduos. Concomitantemente, os casos citados anteriormente desper- 
tam interesse quanto às razões que impediram a concretização de uma gestão autônoma legítima. Neste sentido, a inquietação quanto à necessidade de uma melhor compreensão desta forma de gestão motivou o delineamento de pilares, os quais serão explicitados a seguir.

\subsection{Os pilares da autogestão}

Como argumentado anteriormente, a revisão de literatura realizada sobre a autogestão e temas correlatos, bem como a análise das experiências — sucessos e fracassos - possibilitaram o delineamento de pilares, isto é, elementos que sustentam o exercício da autogestão quando presentes simultaneamente. É interessante destacar que não se trata da definição de um modelo para a autogestão, mesmo porque tal característica contraria as ideias básicas da autonomia e da independência, inerentes a tal forma de gestão, as quais culminam, inevitavelmente, na unicidade das experiências. Trata-se da vivência de uma forma de organização que se baseia principalmente em valores, os quais não são passíveis de planejamento e não podem (ou não devem) ser impostos. Assim como expõe Misoczky e colaboradores (2004), a autogestão não se constitui um modelo acabado. Sua existência, estrutura e organização são resultantes do desejo, do pensamento e da ação dos membros do grupo envolvidos. Neste sentido, o objetivo é destacar aspectos importantes para a autogestão, os quais podem se manifestar de formas diferentes em cada contexto específico.

Partindo desta consideração, defende-se a ideia de que a gestão autônoma repousa sobre três pilares: 1 ) autonomia e equidade no processo decisório; 2) valores humanistas e 3) disponibilidade de conhecimento técnico-administrativo para os membros da organização, todos perpassados por uma lógica de construção social e definidos em oposição ao modo como se apresentam em organizações burocráticas. As dimensões propostas sobrepõem-se e confundem-se, e foram minimamente distendidas para proporcionar maior clareza de sua relevância e da magnitude da mudança em relação à forma de gestão heterônoma.

\subsubsection{A amplitude do tema "poder" e o foco no processo decisório}

O poder é comumente definido como a habilidade de fazer com que outros realizem o que se quer que seja feito, se necessário contra a própria vontade 
dos mesmos. Esse conceito costuma ser o ponto de partida para os trabalhos que tratam desta ampla e controversa temática, embora, a partir dele, Hardy e Clegg (2001) destaquem duas visões que se sobressaem em relação às outras: a funcionalista e a crítica. Esta última está fundamentada na premissa da existência do conflito de interesses, em que o poder se manifesta como dominação de um grupo sobre outro. Em Marx, esta relação deriva basicamente da propriedade sobre os meios de produção, enquanto que, para Weber, além da propriedade, o controle sobre os métodos de produção (o conhecimento das operações, o estabelecimento de normas e regras de conduta laboral) se erige como fator de dominação. Weber, no entanto, enfatiza as formas de identificação e representação, rejeitando o determinismo da estrutura de classes, abrindo a possibilidade de discernimento para os indivíduos na determinação de interesses e de utilização do poder (Hardy e Clegg, 2001).

A perspectiva de poder fundada na premissa do conflito de interesses desdobra-se também em estudos sobre o processo decisório, em que se compreende o poder como um processo capaz de excluir temáticas e interesses da agenda de decisão, aproximando-se assim das estratégias e das táticas que buscam anular a capacidade de discernimento do grupo dominado. Lukes, citado por Hardy e Clegg (2001) e Motta (1981), aponta que o poder poderia ser utilizado a priori para evitar o conflito de interesses através da modelação de percepções, cognições e preferências, de tal modo que os indivíduos aceitassem seu papel na ordem vigente das coisas. Nessa concepção, o poder de definir a realidade é usado pelas classes dominantes para apoiar e justificar sua dominação material, evitando, assim, desafios a sua posição. O poder pode, então, manifestar-se em duas instâncias (objetiva/explícita $\times$ subjetiva/ implícita), sendo mobilizado não somente para se alcançar resultados materiais, mas também para dar a esses resultados algum tipo de significado, legitimando-os e justificando-os através de linguagem, símbolos e ideologias.

Atualmente, a lógica empresarial implica a concentração de saber na administração e de ignorância na produção (Motta, 1981). Nas organizações burocráticas, o poder sobre o processo decisório concentra-se na cúpula administrativa, o que é próprio do modo capitalista de produção, onde a separação entre o operário e os meios de produção cria uma relação autoritária entre capital e trabalho, e a subordinação deste àquele. Configura-se, assim, uma estrutura organizacional cuja hierarquia e normas limitam formalmente o poder decisório dos trabalhadores, mesmo quando e se estes estiverem aptos a influir nas decisões.

A autogestão, em oposição à gestão heterônoma, implica a supressão da estrutura hierárquica e a substituição das normas e regras de conduta formal- 
mente determinadas por normas e regras de conduta socialmente construídas sob um novo paradigma de organização, onde se identificaria a presença da ética, da consciência política e de valores mais humanos e igualitários, como fatores preponderantes. No âmbito intraorganizacional pressupõe-se a simetria de poder no que diz respeito à capacidade objetiva dos atores para definir os interesses específicos da classe/grupo, excluindo a possibilidade de formação de subgrupos capazes de atuar unilateralmente em defesa de interesses não coletivos.

Já no âmbito interorganizacional, a entidade/instituição/grupo/classe deve manter sua autonomia decisória em face de outras entidades/instituições/grupos/classes com as quais se relaciona, para que sua capacidade de determinar e realizar os interesses que lhe são pertinentes não seja enfraquecida em função da posição de "ilhas de autogestão", já discutida anteriormente. Neste trabalho, a dimensão "poder" será utilizada focando-se a capacidade de influência no processo decisório, isto é, a capacidade de definição e realização de interesses objetivos específicos de um grupo ou classe social (Faria, 2001). Consideraremos para isso tanto o âmbito intraorganizacional quanto o interorganizacional.

\subsubsection{A importância de valores humanistas para um modo de produção autogerido}

A dominação nas organizações heterogeridas se dá tanto em uma dimensão objetiva, através de hierarquia, normas e regras formais, quanto subjetiva, através da divulgação da ideologia capitalista burguesa, que tenta criar a aparência de legitimidade para as relações de dominação estabelecidas e limitar a capacidade de autodeterminação dos agentes envolvidos. Segundo Marcuse (1979), nas sociedades de consumo modernas, a ideologia atinge um grau nunca antes alcançado, pois ela inclui-se no próprio processo de produção. O aparato produtivo e as mercadorias e os serviços que ele produz "vendem" o sistema social como um todo e prescrevem hábitos, reações intelectuais e emocionais mais ou menos agradáveis aos consumidores. Nesse sentido, a disseminação de comodidades que reduzem a discrepância entre o nível de vida de trabalhador e patrão afeta a relação entre classes (embora não a invalide), causando sujeição à divisão social do trabalho estabelecida, redução da oposição e da necessidade de libertação.

Entretanto, conforme proposto por Guillerm e Bourdet (1976), somente a consciência de classe possibilitaria aos trabalhadores recursos teóricos 
que orientariam a discussão e defesa de seus interesses, fazendo-os perceber claramente a dominação e exploração (mesmo que na prática seja possível perceber), e a partir daí elaborar e executar um contraponto libertário, cuja prática revelaria "novos" valores para a sociedade. Enquanto a ideologia burguesa funda-se no produtivismo e no consumismo, a ideologia do trabalhador prima pela abolição do trabalho assalariado substituindo-o por nova forma de trabalho livre e pela criação de uma sociedade livre de dominação, onde os indivíduos tenham a oportunidade de contribuir para a satisfação das necessidades e o desenvolvimento de todos.

Assim, o ethos do modo de produção capitalista heterogerido privilegia a individualidade e a livre competição sob um regime "democrático" que não realiza seu conteúdo, a saber, a igualdade social de seus cidadãos, uma vez que garante a igualdade de direitos apenas em teoria, enquanto a prática revela a possibilidade de que aqueles que detêm os meios de comprar a força de trabalho o façam explorando aqueles que não têm outra coisa que vender (Guillerm e Bourdet, 1976). Por sua vez, a sociedade autogerida funda-se nos princípios da igualdade e da liberdade, realizando a democracia de forma plena através da participação de todos os indivíduos no processo decisório, proporcionando o desenvolvimento da consciência política e, sobretudo, a reprodução de valores correspondentes a esta proposta gestionária, dos quais se destacam a cooperação e a solidariedade.

A importância destes valores para o funcionamento da forma autônoma de gestão é destacada por autores (Garcia, 1981; Lima, 2004; Guillerm e Bourdet, 1976; Singer, 2004; Nascimento, 2004) que tratam de diversas temáticas correlatas, tais como o cooperativismo, a economia solidária e as reivindicações esquerdistas (marxismo e anarquismo). Ressalta-se, principalmente, que enquanto o capitalismo se confunde com a 'normalidade' e não requer a conscientização dos valores que lhe subjazem, as práticas autogestionárias só podem desenvolver suas potencialidades se seus protagonistas o desejarem conscientemente. Por isso, atividades permanentes de difusão e educação ideológica tornam-se essenciais para que os empreendimentos autogeridos possam revelar sua potencialidade e se consolidarem como práticas de gestão plenamente aceitas (Singer, 2004). Convém destacar que esta educação não significa uma inculcação de valores por uma vanguarda (elite intelectualmente capaz), como sugere a proposta leninista, mas sim uma construção dos próprios trabalhadores através da conciliação da prática com a teoria. $\mathrm{O}$ ideário autogestionário precisa ser articulado com experiências concretas, para que os trabalhadores, agindo coletivamente, possam aprender a se autogerir (Nascimento, 2004a). 
A essencialidade de valores convergentes com a proposta da autogestão fica ainda mais evidente quando se analisa a teoria e a prática reformista que vem sendo elaborada e implantada ao longo do curso da história. O controle operário (Guillerm e Bourdet, 1976), por exemplo, apesar de apresentar conteúdo reivindicatório para o movimento operário, não chega a ser efetivamente revolucionário, pois as decisões que o operariado impõe para os patrões dão-se sobre questões pontuais, sem questionar a dinâmica do assalariamento ou o papel da diretoria. Assim, atuando sobre questões de interesse imediato, este regime de gestão favorece o interesse dos operários, invertendo momentaneamente a relação de poder entre as classes sem, entretanto, abolir a dinâmica do senhor e do escravo. Os princípios de igualdade e de liberdade interpõem-se justamente para servir de critério valorativo de ação e fornecer a noção de equidade entre todos os seres humanos, evitando que um regime autoritário seja suplantado por outro igualmente autoritário.

\subsubsection{A reintegralização do conhecimento técnico-administrativo}

A Revolução Industrial e as técnicas de administração científica promoveram uma desqualificação do trabalhador através da divisão do trabalho entre as funções de concepção e de execução, além da fragmentação das diversas atividades do processo produtivo em tarefas simples e repetitivas (Tragtenberg, 1980). Com isso, o trabalhador perdeu a possibilidade de empregar sua criatividade e de deliberar sobre o processo produtivo, limitando-se à mera repetição mecânica de gestos, seguindo o ritmo da máquina (Guillerm e Bourdet, 1976). O trabalho configurado sob esta forma deixou de ter um significado de realização para o operário, tornando-se unicamente uma forma de ganhar a vida, desprovido de outro sentido. Assim, em longo prazo, tal subutilização das capacidades humanas dos trabalhadores, aliada à utilização de mecanismos formais e subjetivos de dominação, acarretou a perda do saber-fazer que caracterizava o trabalhador autônomo das oficinas no período pré-capitalista.

É por isso que as técnicas de enriquecimento do trabalho têm sido utilizadas para dar maior efetividade na produção, concedendo aos trabalhadores poder de deliberação sobre detalhes nos aspectos técnicos da produção e conhecimento mais amplo sobre uma série de tarefas. Esta última mudança permite a flexibilização do trabalho e o manejo mais adequado do quadro de trabalhadores conforme as necessidades produtivas, além de facilitar a redução do efetivo de funcionários com a utilização conjunta de máquinas (nesse caso, um trabalhador é capaz de operar diversas máquinas) e criar uma sen- 
sação de participação que aumenta a motivação e o interesse do operário pela obra capitalista.

Para a autogestão, tais medidas são insuficientes. Interessa recompor o sentido do trabalho, integralizando os saberes a respeito do processo produtivo e das funções administrativas da organização, que foram perdidas com o processo histórico de institucionalização de formas heterônomas de gestão, para que se possa garantir a efetividade do poder decisório. Na experiência de gestão iugoslava, por exemplo, a autogestão não chega a se realizar por dois motivos principais (Venosa, 1982; Almeida, 1983; Guilherm e Bourdet, 1976): 1) a centralidade do papel do Estado tanto na concepção do modelo quanto na coordenação das empresas, impedindo assim que a base (os trabalhadores) se manifestasse, ocupando as posições que permitiriam efetivamente a gestão das empresas; 2) no âmbito intraorganizacional, os Conselhos de Trabalhadores contavam com uma participação mais intensa de indivíduos de nível de educação mais elevada (conhecimento técnico ou administrativo), o que resultava em uma distribuição autocrática de poder (Venosa, 1981). Assim, o primeiro ponto encaixa-se mais adequadamente na dimensão do processo decisório analisada anteriormente, enquanto o segundo motivo refere-se justamente à necessidade aqui exposta de reintegralização do conhecimento técnico-administrativo para os trabalhadores.

Vale destacar que tal capacitação não significa que os trabalhadores irão responsabilizar-se pela execução de todas as atividades o tempo todo, mas que fica aberta a possibilidade de rotação das funções, e, principalmente, evitando que os trabalhadores tornem-se meros objetos da determinação alheia, passando a definir conjuntamente as atribuições e as responsabilidades referentes a cada indivíduo em determinado momento com conhecimento de causa. A reintegralização do conhecimento técnico-administrativo para os trabalhadores é essencial para garantir que a efetividade da produção não se perca, sem que isso, no entanto, signifique que o objetivo desta mudança seja a produção mercantil. Nesse ponto, a interseção se dá com a questão dos valores, pois, conforme apresentado na seção anterior, a ideologia de uma sociedade autogerida privilegia o aspecto social da produção em detrimento do aspecto mercantil.

\section{Metodologia}

Esta pesquisa consistiu num trabalho teórico-empírico que buscou analisar a experiência do Programa de Autogestão da Habitação, da Secretaria Municipal de Habitação de Belo Horizonte, à luz de pilares da gestão autônoma. Des- 
se modo, além do exame da literatura disponível sobre o tema, recorreu-se ao estudo de campo, onde foi possível verificar na prática a (não) vivência destes pilares e o impacto da mesma para a configuração da experiência.

A metodologia utilizada consistiu num estudo de caso de caráter descritivo abordando as principais características e processos de funcionamento do Programa de Autogestão da Habitação, suas limitações internas e externas. O estudo teve uma abordagem qualitativa que visa interpretar o fenômeno dando ênfase aos significados que exprime e às experiências que representa para os participantes (Vergara, 2000).

A técnica de coleta de dados incluiu a realização de sete entrevistas com membros da organização estudada, da Prefeitura de Belo Horizonte e da União Estadual por Moradia Popular (Uemp-MG), fornecendo dados a respeito de processos, características e princípios de uma organização autogerida. Tal pesquisa de campo foi realizada a partir de entrevistas in loco e registradas com um gravador a fim de manter a integridade dos dados. Os entrevistados foram numerados de 1 a 7, a fim de preservar suas identidades. Além disso, realizou-se a observação participativa em reuniões de um dos grupos de beneficiados pelo programa, o que complementou a coleta de dados e permitiu acrescentar informações que escapam à ferramenta relacionada.

Por fim, a interpretação e a análise dos dados foram realizadas com base na técnica de análise de conteúdo, de modo a extrair os significados presentes nas entrevistas, relacionando-os com os dados das observações, permitindo uma compreensão o mais ampla possível do fenômeno da autogestão. Utilizaram-se como unidades de análises os pilares apresentados a partir da revisão teórica (Vergara, 2000).

A grande limitação deste estudo consiste em seu escopo restrito, já que se trata de um estudo de caso, não permitindo, portanto, a ampliação de seus resultados como conhecimento genérico sobre a autogestão. Ainda assim, a definição dos pilares e a observância destes na realidade das organizações autogeridas se tornam importantes, na medida em que contribuem para o aprofundamento de uma temática cada vez mais em destaque no contexto atual.

\section{0 caso do Programa de Autogestão da Habitação}

\subsection{Movimento por moradia e origem dos recursos do Programa de Autogestão}

A história da autogestão para habitação, de origem uruguaia, veio para o Brasil na década de 1980 com a realização das primeiras experiências no estado 
de São Paulo. Em Minas Gerais, o primeiro município a adotar políticas para a questão da habitação, vislumbrando práticas de gestão autônoma, foi Ipatinga, ao final da década de 1980. Em Belo Horizonte, foi durante o governo do PT, em 1994, que surgiu a primeira experiência de gestão autônoma, a construção do conjunto Urucuia, resultado de uma política voltada para a resolução do problema de habitação para as famílias de baixa renda. A presença do movimento de luta por moradia teve grande importância neste processo, principalmente através da formação de associações que reivindicavam, por meio de debates com as esferas de poder, soluções para o déficit de moradia.

As políticas de habitação surgiram, assim, como uma iniciativa da Prefeitura de Belo Horizonte (PBH) em resposta a uma demanda social. Atualmente englobam o Orçamento Participativo da Habitação e o Programa de Arrendamento Residencial, criado em 1999, o primeiro ainda se subdividindo em duas formas de gestão: a Gestão Pública e o Programa de Autogestão. Na Gestão Pública, todas as fases de implementação do empreendimento são administradas pelo poder público seguindo a legislação pertinente.

Já na Autogestão, é firmado um convênio com uma Associação Habitacional por meio do qual a PBH se compromete a liberar os recursos necessários para a realização do empreendimento e fiscalizar a realização do mesmo, enquanto a Associação se compromete a executar e administrar o empreendimento com auxílio de uma Assessoria Técnica por ela contratada e que responda aos critérios estabelecidos pela $\mathrm{PBH}$. Entre os objetivos do programa, além de suprir o déficit de moradia, está a possibilidade de gestão dos recursos do empreendimento por parte das famílias, de desenvolvimento do projeto em suas diversas etapas, de participação nas atividades de planejamento e construção, além de promoção da ocupação ordenada do solo urbano.

O Programa de Autogestão utiliza como fonte de recursos o programa de Crédito Solidário, sendo o repasse por família em torno de $\mathrm{R} \$ 20.000,00$. Além deste, a PBH realiza um aporte de $\mathrm{R} \$ 6.000,00$ e também concede o terreno destinado à construção dos conjuntos habitacionais. Os recursos são repassados através da Caixa Econômica Federal (CEF), a qual adota uma série de critérios de aceitação, válidos para todos os conjuntos financiados pelo Crédito Solidário, para que as famílias indicadas pelas associações sejam, de fato, aceitas no programa. Entre estes critérios estão a exigência de renda mínima de dois salários mínimos, avalista, adimplência comprovada, além de uma série de documentos. Entretanto, diante das dificuldades geradas por estes critérios, há uma grande discussão entre as associações e a CEF para alcançar maior flexibilidade dos mesmos. 


\subsection{Etapas do programa}

A participação de um indivíduo ou família no Programa de Autogestão da Habitação constitui o ápice de uma série de ações que fazem parte do movimento por moradia, e, portanto, embora o foco da análise situe-se sobre a fase de projeto e construção de um conjunto habitacional, é importante também expor a parte do processo que começa ainda nas associações de moradores.

As famílias carentes organizam-se em associações em sua maior parte por critérios de regionalidade (bairros, regionais) e atuam como um grupo, em geral, vinculado à União Estadual por Moradia Popular (Uemp). Estas reivindicam a adoção de medidas referentes à política habitacional na $\mathrm{PBH}$, participam da elaboração do Plano Diretor da cidade, marcam presença no Fórum de Reforma Urbana e outros eventos que buscam discutir a questão da falta de moradia, soluções para o problema e apresentar experiências realizadas, além de promoverem reuniões internas que auxiliam a organização e continuidade do movimento. A participação no movimento de luta é de grande importância, pois, conforme apresentado pelos entrevistados, é um dos critérios para a seleção interna que as associações fazem entre seus membros para indicarem aqueles que seriam os beneficiados em cada novo conjunto habitacional construído.

Um exemplo mais detalhado dos critérios e da dinâmica de seleção interna é explicitado com o caso da Associação dos Moradores Sem Casa do Bairro Betânia (Asca), onde são apresentados, por ordem de importância: 1) tempo de participação no movimento; 2) presença em reuniões, assembleias, seminários e outros eventos da associação; 3) contribuição para a associação, podendo ser financeira, trabalhos voluntários ou outras formas que permitam a manutenção do movimento; e 4) urgência da necessidade das famílias, onde o número de filhos da família é utilizado como indicador.

A segunda etapa de seleção é aquela referente aos processos da CEF, conforme abordado anteriormente. Em seguida, o grupo dos beneficiados está formado e começam as etapas referentes ao desenvolvimento do projeto e à construção da moradia. As primeiras reuniões do grupo de beneficiados tratam de temas referentes à organização interna do próprio grupo, sendo discutidas questões como adequação dos perfis e habilidade ou disposição para adquirir os requisitos para ocupação de funções administrativas (compras, registro de materiais, entre outras) e executoras (marceneiros, pedreiros, soldadores, entre outras). Além disso, a escolha a respeito das assessorias é feita neste momento inicial, a partir de indicações das associações. Assim, além do grupo dos futuros moradores, CEF, Associação e Prefeitura, surgem outros agentes 
que auxiliarão todo o processo subsequente, destacando-se as figuras da Assessoria Técnica e da Assessoria Social.

A Assessoria Técnica engloba principalmente arquitetos, engenheiros e advogados que trabalham no processo de planejamento e de construção da moradia, e realizando os trâmites jurídicos para liberação de verbas, regulamentação dos processos, contratos, projetos, cálculos, estimativas e demais documentos necessários. A Assessoria Social é composta principalmente de assistentes sociais e sua função é realizar a integração dos moradores, explicar e desenvolver o sistema autogestionário junto à comunidade, discutir os conceitos de moradia e condomínio para conscientizar as pessoas, além de promover atividades (visitas ao local da construção e a outros conjuntos habitacionais, palestras) e outras formas dinâmicas de integração e conscientização dos futuros moradores que permitam criar um respeito mútuo e reduzir as possibilidades de conflito.

Estas assessorias são selecionadas pelo próprio grupo beneficiado, podendo provir de escritórios particulares, universidades ou de órgãos públicos. Os membros entrevistados do grupo parecem se identificar mais com a assessoria social do que com a assessoria técnica, o que reflete no modo de relacionamento entre cada um dos agentes. Assim, a relação com a assessoria técnica é vista como uma relação de prestação de serviços que pode ser desfeita a qualquer momento se o corpo assessor não cumprir as expectativas em relação aos desígnios do grupo. Já a assessoria social, sempre presente nas reuniões, e muitas vezes coordenando e mediando o processo de tomada de decisão coletiva, está mais próxima do grupo, e a percepção sobre seu papel é mais difusa e menos contrastante com o grupo.

Os passos seguintes são a discussão, com auxílio da assessoria técnica, das questões relativas ao projeto arquitetônico, a tomada de decisões sobre como será feita a obra, se haverá o uso de mutirão e a modalidade dele (somente aos fins de semana ou também durante a semana, voluntário ou remunerado, com serviços leves como jardinagem e limpeza, ou se diretamente na obra), e a decisão de questões sobre contratação do serviço de terraplanagem, compra de materiais e outros pontos necessários para o início da obra. Já a etapa seguinte diz respeito à construção propriamente dita, onde são acertados o regulamento de obra, definidas comissões de obra e onde aos poucos o projeto vai sendo desenvolvido. Por fim, o processo se completa através do acompanhamento realizado ao final da conclusão da obra, fase chamada de Pós-Morar, mas que não vem sendo implementada nas experiências que ocorreram, devido à alegação de falta de recursos por parte da $\mathrm{PBH}$ para tal. 
Outro ponto importante refere-se à criação de condições econômicas suficientes para que os futuros moradores dos conjuntos habitacionais tenham condição de permanecer em sua moradia arcando com as obrigações existentes, ou, ainda, no sentido de evitar que vendam seus imóveis para angariar um benefício monetário elevado em curto prazo, mas continuem vivendo em condições precárias de habitação e vida. O Programa da Autogestão não apresenta também nenhuma determinação específica nesse sentido, e os entrevistados afirmaram que a preocupação se dá quase que exclusivamente sobre a questão da moradia, num horizonte imediato. No máximo, o que foi afirmado por parte da prefeitura é que cada conjunto tem liberdade para utilizar o espaço comum empregando-o em atividade econômica, se assim desejarem.

\subsection{Análise dos pilares da autogestão no Programa de Autogestão da Habitação}

\subsubsection{A configuração do poder}

Ao analisarmos a configuração de poder no interior do grupo de moradores beneficiados, pôde-se perceber a possibilidade que os participantes têm de atuar nas diversas etapas do projeto e a influência que exercem no processo decisório. Assim, tem-se uma efetividade de poder detido pelos participantes, e simetria entre eles, de modo que todos têm iguais oportunidades para opinar nos assuntos apresentados e influir no processo decisório. Apesar disso, foi possível constatar que nem sempre os participantes exercem o poder de decisão plenamente, por diversos motivos que incluem, principalmente, a falta de interesse em determinados assuntos, a incapacidade de argumentação e defesa de interesses, o medo de se responsabilizar caso o ponto de vista seja adotado, entre outros.

Destaca-se que, muitas vezes, regras e determinações criadas em experiências anteriores de gestão autônoma na habitação são utilizadas como base para discussão e elaboração de normas e procedimentos a serem adotados. A utilização destas experiências confere agilidade ao processo, mas não limita a capacidade de influência que os beneficiados detêm sobre tais decisões, pois todos os pontos debatidos em que surgem dúvidas ou oposições são detalhados para que os presentes nas reuniões possam compreender o assunto e realizar uma escolha consciente sobre os impactos que tal decisão teria sobre o processo. Outro ponto que envolve a necessidade de participação dos membros refere-se ao processo de seleção dos beneficiados anteriormente apresentado, 
visto que, em casos de urgência de moradia, o grupo pode decidir em favor de uma família, mesmo que esta não atenda aos demais critérios estabelecidos.

Em relação aos agentes externos que atuam no processo e potencialmente podem influir no processo decisório, destaca-se inicialmente o relacionamento com a prefeitura, que se dá mais intensamente pelo movimento em prol da moradia como um todo do que especificamente em relação a um grupo de beneficiados participantes do programa. O relato apresentado pelo entrevistado 2 indica a existência de um relacionamento bastante conflituoso, cuja razão alegada é a indisposição da administração pública em manter um diálogo aberto com a comunidade. Afirma, ainda, que não é de interesse das prefeituras realizar tal tipo de ação voltada para suprir o déficit de moradia, uma vez que as moradias para a população carente estão localizadas na periferia e, portanto, não geram visibilidade para o governo.

O movimento pela moradia busca, cada vez mais, uma independência em relação aos órgãos governamentais, utilizando-os apenas como forma de financiamento, desejando que não haja uma intervenção muito grande, principalmente devido à burocracia, pois gera atrasos e constrangimentos para as famílias que buscam suas moradias próprias. Apesar disso, no relacionamento com a prefeitura, casos de cooptação de membros originalmente ligados ao movimento costumam ocorrer, embora o movimento como um todo permaneça razoavelmente independente.

Focando o grupo beneficiado, a figura da administração pública exerce atividades de controle e verificação a cada etapa do projeto, para que os recursos para a fase subsequente sejam liberados. Tais atividades surgem como uma adversidade, pois se considera que os atrasos nas obras são consequência da lentidão na aprovação da prestação de contas fornecida pela organização autônoma, e, em geral, que o processo adotado no Programa de Autogestão da Habitação ainda é extremamente burocrático e moroso. A CEF é outro agente que tem participação decisiva, pois detém poder de veto sobre as indicações fornecidas pelas associações no momento da escolha das famílias beneficiadas. Assim, há uma grande tensão nas relações entre os diversos agentes envolvidos ao longo do processo.

Na visão dos beneficiados entrevistados, a existência dos critérios seletivos da CEF é vista como uma burocracia excessiva, que deve ser adaptada ao contexto das famílias carentes. Algumas conquistas conseguidas no sentido da flexibilização incluem, por exemplo, aceitação de renda informal para comprovação de renda; aceitação de avalista na figura da própria associação da qual o morador faz parte; inclusão no programa se o beneficiado tiver "nome limpo" no sistema de proteção ao crédito pelo menos um dia antes da 
avaliação (em casos normais de crédito, é preciso seis meses de antecedência); aceitação de documentos autenticados na associação. Apesar disso, foi afirmado que ainda existem barreiras demais para a aceitação de famílias, o que também causa lentidão no processo, pois é preciso esperar até que o número de famílias aceitas nos critérios da CEF complete o número de famílias previsto para cada conjunto.

Quanto à Assessoria Técnica, a relação com a associação inclui-se na ótica da prestação de serviços, ou seja, cria-se uma subordinação formal da assessoria aos desígnios do grupo beneficiado. Para os associados, as assessorias técnicas possuem o poder técnico, no sentido de tentar convencer os beneficiados a seguirem as especificações determinadas por eles. Por outro lado, os coordenadores, representantes do grupo de beneficiados que fazem o contato mais direto com os diversos agentes externos, são vistos como astutos, sem se deixar levar pela influência dos técnicos, sabendo dialogar com os assessores de maneira a chegar à solução mais próxima ao ideal para os moradores. De modo geral, na visão dos beneficiados, a relação entre eles e os agentes externos é considerada como um conflito positivo, e que gera aprendizado para os dois lados (para os moradores, agrega alguns conhecimentos técnicos e, para as assessorias, ensina a trabalhar com outros públicos, como os populares).

Porém, é importante ressaltar que, similar ao que ocorreu em Ipatinga (Conti, 1999), onde as relações entre associação e assessoria técnica sempre foram problemáticas, a configuração de uma relação de subordinação, mais do que uma relação de parceria, pode tornar a assessoria uma mera executora de cálculos e outros trabalhos técnicos. Desse modo, limita-se a amplitude da troca de experiências e de desenvolvimento mútuo que uma relação de igual para igual pode proporcionar, e inverte-se para uma relação de autoridade, privilegiando o grupo beneficiado, mas sem destituir a lógica patrão-empregado.

\subsubsection{A questão dos valores}

Em experiências de gestão coletiva, o componente social merece destaque, pois representa a disposição política para que sejam feitas as discussões, tomadas as decisões e praticadas as ações que levam a comunidade a adquirir benefícios, de forma que não prioriza apenas os interesses individuais, mas também se considera e respeita os outros indivíduos.

Na visão dos entrevistados, o processo de construção de moradias através de autogestão permite o desenvolvimento da cidadania. Assim, aprende-se a conviver com as outras pessoas, a se conhecer e respeitar mutuamente, e a 
desenvolver um sentido de companheirismo, que vai desde a reunião em associação para reivindicar o direito à moradia digna, passando pelas reuniões decisórias e pelos momentos de trabalho nos mutirões, chegando à vida estabelecida na comunidade do conjunto habitacional.

"A questão do mutirão é justamente pras famílias se conhecerem. É mais pra você estar do lado do companheiro, pra você se adequar ao estilo de vida dele, e ele ao seu. Criar um vínculo social porque amanhã você está de parede 'de meia' com o indivíduo ali” (entrevistado 3).

A ênfase dada à forma de organização para construção como catalisador para a aproximação entre as famílias e a formação de comunidades é intensa e ainda tem outro efeito sob a perspectiva meramente individual: a valorização do bem conquistado. É relatado que as famílias atribuem um valor muito maior à moradia adquirida sob processo de autogestão do que de outra forma e, por isso, não desejam mudar de local de moradia, pois representa uma conquista que não se restringe ao bem em si, em função de todas as lutas e todo o esforço necessário para adquirir a moradia. Ou seja, cria-se uma identificação da história de vida individual e a história da moradia. Outro ponto curioso é que os moradores adquirem conhecimento sobre a estrutura da casa, onde existem os canos, qual o tamanho de cada cômodo, qual a área total construída, que normalmente não dispõem e que ajuda a intensificar o valor atribuído ao bem.

Apesar da importância atribuída à forma de gestão autônoma, foi possível detectar indícios de desvalorização da utilização de trabalho próprio na construção da moradia, sendo relatados movimentos de terceirização e baixa participação dos beneficiados nos cursos de formação profissional.

[...] mas eu achava melhor mesmo colocar uma construtora, mas ninguém tem condições, e fica muito caro, e a gente não tem dinheiro. O dinheiro está preso, está na Caixa, e eles liberam por etapa, mas eu achava melhor empregar, contratando uma construtora pra pôr pra gente, pra trabalhar aqui e entregasse assim, só acabamento. Levantado o imóvel, entregasse só no acabamento e aí a gente terminava (entrevistada 5).

Conforme indicado anteriormente, esta consideração deve ser vista à luz da limitação de recursos e da regulação do tempo presentes nos projetos, mas não deixa de constituir um ponto negativo na questão dos valores, pois, ao retomarmos a noção mais ampla da autogestão, tal comportamento indicaria a existência de solidariedade e companheirismo apenas dentro dos limites do grupo beneficiado, restando aos relacionamentos externos a mesma base 
de critérios utilitários e valores individualistas associados às formas heterônomas de gestão.

Outro ponto negativo percebido nas reuniões dos beneficiados é a falta de participação efetiva e o grau relativamente baixo de comprometimento dos presentes, visto que do total de beneficiados pelo Residencial Serra Verde, $50 \%$ estavam presentes. E ainda, entre os presentes, percebeu-se grande falta de atenção e desinteresse em relação às discussões, constantes conversas paralelas, o que remete às formas falsas de participação. Parte dessa falta de comprometimento pode ser resultado de um sistema de pontuação que bonifica as presenças nas reuniões e nos demais eventos relacionados ao desenvolvimento do projeto, servindo como critério para seleção do apartamento (os participantes que detêm maior número de pontos adquirem prioridade para a seleção do apartamento). Paradoxalmente, um mecanismo criado para estimular a presença e garantir a coletividade na tomada de decisões acaba estimulando a competitividade para seleção dos apartamentos e incitando formas passivas de participação.

\subsubsection{Conhecimento técnico-administrativo}

Os principais pontos referentes a este pilar dizem respeito ao relacionamento entre assessoria técnica e o grupo beneficiado e também à pequena importância conferida aos processos de capacitação e treinamento dos futuros moradores. Ao primeiro caso, já explicitado na questão do poder, deve-se acrescentar que a existência de uma relação de subordinação, ou ainda uma parceria entre os dois agentes, não elimina a superioridade em termos de conhecimento técnico possuído pela equipe de assessoria. Tal superioridade é conhecida e aceita, de modo que os beneficiados parecem limitar seu campo de ação e confiar nas alternativas e propostas realizadas pelos assessores. Assim, por mais que apontem a possibilidade de trocar de equipe de assessoria, este fato nunca ocorreu, e a relação de aprendizado mútuo indicada pode camuflar um desequilíbrio de poder originado da falta de conhecimento por parte dos beneficiados.

A principal dificuldade de compreensão é a questão do conhecimento. O conhecimento técnico é diferente do conhecimento deles. Nem sempre é fácil a gente conseguir chegar no nível de entendimento deles. [...] Na verdade tem dois tipos de decisão. Tem uma decisão que é técnica, que essa decisão não se discute. [...] Não vou levar pra eles que tipo de fundação, se vai ser uma estaca, 
um tubulão, uma sapata, esse tipo de decisão não passa por eles porque eles não têm argumento técnico pra discutir isso (entrevistado 7).

Ainda podem-se notar, também, problemas decorrentes dessa falta de conhecimento técnico e administrativo, como atrasos na obra e dificuldades para tomada de decisões.

Eles colocaram lá (em outro empreendimento) uma Comissão de Moradores que deveria assim, entender um pouquinho mais de obra [...] Porque tem gente que vai lá pra poder assinar pela Comissão de Obra que nunca viu obra na vida. Então falta conhecimento da obra. [...] o cara que está ali pra fiscalizar a obra, ele não tem conhecimento nenhum e é onde está surgindo problema. A obra lá está atrasada mais de seis meses (entrevistado 3).

Eu, pra te falar a verdade não entendo não (o processo de gestão). Eu não compreendo o que eles falam aí da verba, o negócio do dinheiro da Caixa, que tudo tem que ter o serviço pra poder soltar o dinheiro (entrevistado 5).

Em relação ao segundo ponto, argumenta-se que, para que os participantes de um projeto deste tipo possam efetivamente contribuir em seu desenvolvimento, considera-se importante que os beneficiados tenham algum tipo de treinamento para capacitação em alguma função da organização, seja administrativa ou técnica. Apesar disso, verificou-se que as atividades de formação e capacitação não são tão difundidas ou requisitadas por nenhuma das partes envolvidas no processo.

Por outro lado, existem alguns relatos de membros que participaram de cursos e que se "formaram no canteiro de obras", começando com atividades de pedreiro e chegando a mestre de obras na atualidade. O Residencial Serra Verde, por almejar ser um modelo, prevê esses cursos de treinamento e formação profissional, principalmente aqueles relacionados aos trabalhos na obra, que facilitariam o processo e gerariam certa qualificação para os envolvidos.

Um dos motivos possíveis para que a questão do treinamento não seja tão presente nas experiências anteriores e que ele não seja amplamente requisitado pela comunidade diz respeito à própria disposição dos beneficiados.

Muitas vezes elas não estão interessadas em fazer isso. [...] teve um conjunto que eu pesquisei mais a fundo que apareceram duas ou três pessoas querendo, mesmo, trabalhar na obra, [...] participar e fazer como profissão. É até surpreendente, porque a gente acha que vai dar uma boa oportunidade pra eles [...] (entrevistado 1). 
A ideia é que o maior número de famílias pudessem participar, não sei o que aconteceu, mas poucas famílias aderiram a esse curso e daí foi aberto a pessoas externas. [...] A gente imaginou que tivesse uma procura maior, eu pelo menos pensei isso, mas não foi o que houve não (entrevistado 7).

Entretanto é importante ressaltar que tal capacitação também se vê vinculada à modalidade de construção, que nem sempre é feita em mutirão, ou às vezes inclui mutirão apenas aos fins de semana, e até mesmo envolvido apenas com atividades de limpeza e jardinagem e, neste sentido, os membros não se sentiriam motivados a investir em uma formação. Outra hipótese aventada é que a contratação de terceiros para a obra pode representar uma opção menos onerosa e mais ágil, e que devido à restrição dos recursos e à necessidade de cumprir o planejamento para evitar problemas com os outros agentes envolvidos, torna-se mais interessante do que a efetiva participação na execução da obra.

Quanto às questões administrativas, não há também nenhuma evidência de que existam cursos, palestras ou qualquer tipo de orientação que auxilie o exercício desse tipo de função. "Nas questões administrativas eu não sei se tem alguma formação. Mas eu acredito que tenha liberdade de haver essa formação se o corpo social quiser ter, acredito que tenha essa possibilidade, não sei se acontece" (entrevistado 1 ).

Neste sentido, percebe-se que a questão do conhecimento técnico-administrativo é um ponto fraco na experiência analisada. A constatação de que tal fato está principalmente relacionado à falta de interesse dos membros é preocupante, na medida em que a autogestão exige uma postura mais ativa dos mesmos. Mais uma vez pode-se retomar a importância da participação e do envolvimento com a proposta, pois, como já discutido, a busca por maior aprimoramento e conhecimento significa se colocar em posição de maior igualdade para discutir e propor ideias sobre um projeto que está diretamente relacionado com a vida de cada um.

\section{Considerações finais e sugestões para novas pesquisas}

Este trabalho apresentou e discutiu os principais temas que se relacionam com a autogestão, delimitando-se, a partir disso, pilares que visam contribuir para a análise de organizações autogeridas. Realizou-se um estudo de caso do Programa de Autogestão da Habitação da Prefeitura de Belo Horizonte, sendo possível conhecer, descrever e avaliar tal iniciativa à luz destes pilares apre- 
sentados. De modo geral, pôde-se perceber que a vivência dos pilares não se dá de forma completa, o que de certa maneira impede que a autogestão seja exercida integralmente.

Em geral, o Programa permite um resgate da dignidade e contribui para a autonomia das pessoas, na medida em que possibilita que estas participem das decisões relacionadas ao empreendimento. Internamente ao grupo há uma maior simetria, entretanto, verificou-se que nem todos os participantes atuam ativamente nas reuniões, demonstrando algum desinteresse e falta de compromisso com a proposta. Já externamente, em razão dos diversos vínculos e relacionamentos com entidades externas e pela própria falta de capacidade para exercício efetivo desse poder, principalmente pelas limitações legais e técnicas, as decisões a serem tomadas pelo grupo tornam-se restritas, o que de certa forma descaracteriza a autogestão.

Em relação aos valores, a presença de solidariedade e cooperação é percebida grandemente no interior das associações de moradores e dos grupos de beneficiados, apesar de existirem ainda dificuldades em relação à maior extensão na aplicação destes valores em relação às entidades externas. Destaca-se que mesmo os beneficiados de conjuntos anteriores continuam ativos no movimento, apoiando aqueles que ainda não foram contemplados e que vivem em situação mais precária de habitação.

Esta forma de gestão parece ter um efeito mais significativo do ponto de vista dos beneficiados quanto à fixação das famílias em suas novas residências, através da criação de um vínculo identitário-afetivo com o imóvel, além de proporcionar o desenvolvimento da cidadania através do aprendizado político coletivo e da criação ou ampliação do senso comunitário. Individualmente, pode ainda auxiliar o aprendizado profissional, proporcionando expectativas de emprego e renda aos indivíduos envolvidos.

Quanto ao conhecimento técnico-administrativo, este demonstra ser uma das maiores lacunas entre os pilares apresentados, pois há evidente limitação na capacidade decisória e na participação mais ampla em algumas etapas do processo (avaliação e controle) dos beneficiados em virtude de conhecimento específico para tal. Os beneficiados parecem perceber esta situação como natural e não demonstram grande interesse em ampliar seu conhecimento, submetendo-se às "sugestões" dos grupos técnicos e aceitando a participação de outros agentes, capacitados para realizar as funções.

De modo geral, a análise do caso específico e, de forma mais ampla, da temática da autogestão suscita questões como a razão de tamanho desinteresse dos indivíduos e sobre como tornar os valores - tão essenciais para a vivência deste modo de gestão — significativos para os indivíduos. A proposta 
educacional se faz presente na maior parte dos trabalhos sobre o assunto e, realmente, esta possui um papel fundamental. No entanto, ressalta-se que é preciso, antes de tudo, que os indivíduos mostrem-se interessados nesta mudança de perspectiva.

Outras questões relevantes referem-se ao papel da prefeitura, isto é, do Estado neste contexto. Como desenvolver projetos que contribuam para a disseminação destas novas formas organizacionais sem que este incentivo interfira na autonomia dos mesmos? Ou, como já mencionado, como desenvolver estes projetos sem que isso constitua apenas uma forma de passar para as mãos da sociedade papéis de responsabilidade do poder público? Ainda faz-se necessário discutir sobre as declarações de beneficiados acerca do desinteresse do governo neste tipo de empreendimento, o que seria decorrente da pouca visibilidade destes projetos. Seriam tais afirmações verdadeiras? Ou seja, essas ações seriam apenas iniciativas pontuais para silenciar os movimentos que lutam e cobram do governo melhores condições de vida? Estas questões constituem-se sugestões para novas pesquisas, pois devem ser discutidas a fim de contribuir para o desenvolvimento tanto destas outras formas organizacionais, quanto para a própria gestão pública no que tange à busca por um caminho cada vez mais democrático.

Apesar de não configurar uma experiência autogestionária "completa", o caso do Programa de Autogestão da Habitação não deixa de representar uma iniciativa que caminha positivamente na direção de modos de gestão mais democráticos, em que a participação e a autonomia dos indivíduos, associadas à solidariedade e à cooperação, permitem um desenvolvimento amplo para todos os envolvidos. Resta, portanto, a observância de pontos importantes discutidos para que a autogestão, de fato, seja vivenciada e, a partir daí, possa representar um avanço ainda maior em termos de cidadania, política e democracia.

\section{Referências}

ALMEIDA, Heloísa Maria Mendes. Autogestão: da ideia às práticas. Revista de Administração de Empresas, Rio de Janeiro, v. 23, n. 1, p. 37-57, jan./mar. 1983.

BAETA, Adelaide Maria Coelho; SIQUEIRA, Moema Miranda. Mitos e potencialidades da participação em saúde. Revista de Administração de Empresas, Rio de Janeiro, v. 24, n. 4, p. 30-33, out./dez. 1984. 
BERTHIER, René. Concepções anarco-sindicalistas da autogestão. In: BERTHIER, René; LEVAL, Gaston; MINTZ, Frank. Autogestão e anarquismo. São Paulo: Imaginário, 2002. p. 61-73.

CONTI, A. A experiência da autogestão em Ipatinga: uma busca pelo conceito. 1999. $215 \mathrm{fl}$. Dissertação (mestrado em arquitetura e urbanismo) — Universidade Federal de Minas Gerais, Belo Horizonte, 1999.

FARIA, José Henrique. Poder e participação: a delinquência acadêmica na interpretação Tragtenberguiana. Revista de Administração de Empresas, São Paulo, v. 41, n. 3, p. 70-76, jul./set. 2001.

FRANÇA FILHO, Genauto Carvalho; LAVILLE, Jean-Louis. Economia solidária: uma abordagem internacional. Porto Alegre: Editora da UFRGS, 2004.

GARCIA, Ramon Moreira. Os requisitos de um programa de treinamento de cooperativas. Revista de Administração de Empresas, Rio de Janeiro, v. 21, n. 1, p. 39-45, jan./mar. 1981.

GUILLERM, Alain; BOURDET, Yvon. Autogestão: uma mudança radical. Rio de Janeiro: Zahar, 1976.

HARDY, Cynthia; CLEGG, Stewart. Alguns ousam chamá-lo de poder. In: CALDAS, Miguel; FACHIN, Roberto; FISCHER, Tânia (Org.). Handbook de Estudos Organizacionais. São Paulo: Atlas, 2001. v. 2, p. 260-289.

LIMA, Jacob Carlos. O trabalho autogestionário em cooperativas de produção: o paradigma revisitado. RBCS, São Paulo, v. 19, n. 56, p. 45-62, out. 2004.

MARCUSE, Herbert. A ideologia da sociedade industrial: o homem unidimensional. 5. ed. Rio de Janeiro: Zahar, 1979.

MINTZ, Frank. Ensinamentos da autogestão espanhola. In: BERTHIER, René; LEVAL, Gaston; MINTZ, Frank. Autogestão e anarquismo. São Paulo: Editora Imaginário, 2002. p. 75-91.

MISOCZKY, Maria Ceci Araújo; OLIVEIRA, Romualdo Paz de; PASSOS, Rafael Pavan. Reflexões sobre a autogestão a partir da experiência da Cidade das Cidades. Organização e Sociedade, Salvador, v. 11, ed. especial, p. 183-196, 2004.

MOTTA, Fernando Cláudio Prestes. Burocracia e autogestão: a proposta de Proudhon. São Paulo: Brasiliense, 1981.

- O autonomismo e a questão da organização. Revista de Administração de Empresas, Rio de Janeiro, v. 26, n. 1, p. 57-66, jan./mar. 1986 a.

. Organização e poder: empresa, Estado e escola. São Paulo: Atlas, 1986b. 
NASCIMENTO, Cláudio. Autogestão e o "novo cooperativismo". Brasília: Secretaria Nacional de Economia Solidária, Ministério do Trabalho e Emprego. maio 2004a. Textos para discussão. Disponível em: <www.mte.gov.br/empregador/EconomiaSolidaria/TextosDiscussao/Conteudo/autogestaocooperativismo.pdf $>$. Acesso em: 6 out. 2006.

. Do "Beco dos Sapos" aos canaviais de Catende. Brasília: Secretaria Nacional de Economia Solidária, Ministério do Trabalho e Emprego, maio 2004b. Textos para discussão. Disponível em: <www.mte.gov.br/empregador/EconomiaSolidaria/TextosDiscussao/Conteudo/becosapos.pdf>. Acesso em: 31 out. 2006.

SINGER, Paul. Introdução à economia solidária. São Paulo: Fundação Perseu Abramo, 2002.

. Desenvolvimento: significado e estratégia. Brasília: Secretaria Nacional de Economia Solidária, Ministério do Trabalho e Emprego, maio 2004. Textos para discussão. Disponível em: <www.mte.gov.br/empregador/EconomiaSolidaria/ TextosDiscussao/Conteudo/desenvolvimentoestrategica.pdf $>$. Acesso em: 5 out. 2006.

TRAGTENBERG, Maurício. Administração, poder e ideologia. São Paulo: Moraes, 1980.

VENOSA, Roberto. A evolução da participação nas organizações autogeridas iugoslavas. Revista de Administração de Empresas, Rio de Janeiro, v. 21, n. 1, p. 47-54, jan./mar. 1981.

. A institucionalização de tipologias organizacionais. Um estudo de caso: a autogestão na Iugoslávia. Revista de Administração de Empresas, Rio de Janeiro, v. 22, n. 2, p. 23-36, abr./jun. 1982.

VERGARA, Sylvia Constant. Projetos e relatórios de pesquisa em administração. 3. ed. São Paulo: Atlas, 2000. 